\title{
Rescue Adjuvant Vaginal Progesterone May Improve Outcomes in Cervical Cerclage Failure
}

\author{
Zusätzliche vaginale Verabreichung von Progesteron \\ kann das Outcome bei Versagen der Cerclage verbessern
}

\section{(ㄷ) (i) (오) $\ominus$}

\section{Authors}

Alina R. Roman ${ }^{1}$, Fabricio Da Silva Costa ${ }^{2}$, Edward Araujo Júnior ${ }^{3}$, Penelope M. Sheehan ${ }^{1,4}$

Affiliations

1 Pregnancy Research Centre, Royal Women's Hospital, Melbourne, Victoria, Australia

2 Department of Obstetrics and Gynaecology, Monash University and Monash Ultrasound for Women, Clayton, Victoria, Australia

3 Department of Obstetrics, Paulista School of Medicine Federal University of São Paulo (EPM-UNIFESP), São PauloSP, Brazil

4 Department of Obstetrics and Gynaecology, University of Melbourne, Melbourne, Victoria, Australia

Key words

cerclage, preterm birth, progesterone, short cervix

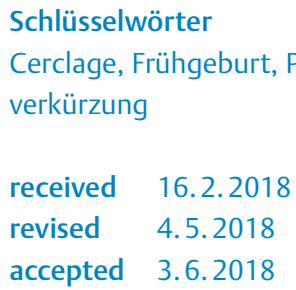

Bibliography

DOI https://doi.org/10.1055/a-0637-9324

Geburtsh Frauenheilk 2018; 78: 785-790 @ Georg Thieme Verlag KG Stuttgart · New York | ISSN 0016-5751

Correspondence

Prof. Edward Araujo Júnior, PhD

Department of Obstetrics, Paulista School of Medicine -

Federal University of São Paulo (EPM-UNIFESP)

Rua Belchior de Azevedo, 156 apto. 111 Torre Vitoria,

São Paulo-SP, CEP 05089-030, Brazil

araujojred@terra.com.br

\section{ABSTRACT}

Introduction Aim of the study was to evaluate the effect of rescue adjuvant vaginal progesterone in women with ongoing, transvaginal ultrasound (TVUS)-confirmed cervical shortening despite cervical cerclage.

Materials and Methods A retrospective case control study was performed of women undergoing cervical surveillance following either history- or ultrasound-indicated cervical cerclage. We compared women managed with cervical cerclage and vaginal progesterone to women managed with cervical cerclage alone. Women with a singleton pregnancy who underwent cervical cerclage were identified from a database. Data on the concurrent use of vaginal progesterone, cervical length measurements, interventions and birth outcomes were collected from patient notes and clinical pathology notes. Patients from each intervention group were matched, based on exact shortest cervical length measurements obtained during surveillance and age of gestation when the measurement was obtained.

Results 66 women were matched and included in the study, based on exact shortest cervical length measurements. Each group had an identical mean shortest cervical length of $12.09 \mathrm{~mm}$. The outcomes of 33 women who received both cervical cerclage and vaginal progesterone were compared to the outcomes of 33 women who were treated with cervical cerclage alone. The administration of vaginal progesterone to women with ongoing cervical shortening despite cervical cerclage was found to significantly prolong the pregnancy ( 36.36 weeks vs. 32.63 weeks; $p=0.0036$ ) compared to women treated with cerclage alone. This use of rescue adjuvant vaginal progesterone was also associated with higher birth weights ( $2829 \mathrm{~g}$ vs. $2134 \mathrm{~g}$; $\mathrm{p}=0.0065$ ) compared to women who had cervical cerclage alone; however, there was no difference in Apgar scores, composite neonatal morbidity or neonatal intensive care admission.

Conclusion Women with cervical shortening despite the presence of cervical cerclage may benefit from further TVUS cervical length surveillance and the administration of vaginal progesterone if further cervical shortening occurs. Despite both groups having clinically significant shortened cervical 
lengths and cervical cerclage in situ, adjunct vaginal progesterone treatment resulted in older gestational age at birth and higher birth weight. Further investigation and confirmation of this finding in a larger prospective trial is warranted to explore this potential benefit for the management of preterm birth in future.

\section{ZUSAMMENFASSUNG}

Einleitung Ziel dieser Studie war es, die Auswirkung von vaginal verabreichtem Progesteron bei Frauen mit fortlaufender Gebärmutterhalsverkürzung trotz Cerclage zu untersuchen. Die Gebärmutterhalsverkürzung wurde mithilfe von transvaginalem Ultraschall (TVUS) gemessen.

Material und Methoden Es wurde eine retrospektive Fallkontrollstudie durchgeführt von Frauen, die sich einer Cerclage unterzogen wegen vorangegangener Anamnese oder wegen mit Ultraschall gemessener Gebärmutterhalsverkürzung. Frauen, die zusätzlich zur Cerclage auch vaginal verabreichtes Progesteron erhielten, wurden mit Frauen verglichen, die nur mit Cerclage behandelt wurden. Für die Studie wurden Frauen mit Einlingsschwangerschaft, die sich einer Cerclage unterzogen, in einer Datenbank identifiziert. Aus den Krankenakten und den Pathologieberichten wurden Daten über die gleichzeitige vaginale Verabreichung von Progesteron sowie Messungen der Gebärmutterhalslänge, sonstige Eingriffe und Geburtsergebnisse gesammelt. Es wurde ein Matching von Patientinnen aus den 2 Interventionsgruppen durchgeführt. Matching-Kriterien waren die kürzeste gemessene Gebärmutterhalslänge sowie das Gestationsalter bei der Messung der Gebärmutterhalslänge.
Ergebnisse Insgesamt konnte ein Matching bei 66 Frauen durchgeführt werden, die daraufhin in die Studie aufgenommen wurden. Die durchschnittlich kürzeste Gebärmutterhalslänge betrug 12,09 mm in beiden Gruppen. Die Ergebnisse von 33 Frauen, die sowohl Cerclage als auch vaginal verabreichtes Progesteron erhielten, wurden mit denen von 33 Frauen verglichen, die nur mit Cerclage behandelt wurden. Die vaginale Verabreichung von Progesteron bei Frauen mit fortlaufender Gebärmutterhalsverkürzung trotz Cerclage hat die Schwangerschaftsdauer signifikant verlängert (36,36 Wochen vs. 32,63 Wochen; $p=0,0036$ ) verglichen mit Frauen, die nur Cerclage erhielten. Der Einsatz von vaginal verabreichtem Progesteron ging auch mit einem höheren Geburtsgewicht einher ( $2829 \mathrm{~g}$ vs. $2134 \mathrm{~g} ; \mathrm{p}=0,0065)$ verglichen mit Frauen, die nur Cerclage erhielten. Es gab aber keine Unterschiede in den Apgar-Werten, der neonatalen Morbidität oder der Einweisung in eine Neugeborenen-Intensivstation zwischen den 2 Gruppen.

Schlussfolgerung Frauen mit fortlaufender Gebärmutterhalsverkürzung trotz Cerclage könnten von einer weiteren Überwachung des Gebärmutterhalses mit TVUS sowie der vaginalen Verabreichung von Progesteron profitieren, falls sich ihr Gebärmutterhals weiterhin verkürzt. Obwohl die Gebärmutterhalslänge in beiden Gruppen signifikant verkürzt war und alle Frauen in beiden Gruppen eine Cerclage bekommen hatten, führte die zusätzliche Behandlung mit vaginal verabreichtem Progesteron zu einem höheren Gestationsalter bei der Geburt sowie einem höheren Geburtsgewicht. Weitere Untersuchungen werden benötigt, um diese Ergebnisse und den potenziellen Nutzen für das Management der drohenden Frühgeburt in einer größeren prospektiven Studie zu bestätigen.

\section{Introduction}

Preterm birth (PTB) remains a major cause of neonatal morbidity and mortality. Cervical length, as measured by transvaginal ultrasound (TVUS), has been shown to be an accurate, reproducible measure and an important predictor of PTB [1-3].

In the general obstetric population, cervical lengths are normally distributed and when shortened, the risk of PTB significantly increases [1-4]. An inverse relationship between cervical length and risk of PTB has been demonstrated, where the likelihood ratio of PTB decreases linearly with increasing cervical length above $20 \mathrm{~mm}$ [5].

Interventions to prevent PTB in the setting of risk factors or asymptomatic TVUS-detected cervical shortening include cervical cerclage progesterone and cervical pessaries. Cervical cerclage has been described and used from the 1950s [6-8]. Early results were conflicting due to difficulties in patient selection and in predicting women who were at high risk of preterm labour $[9,10]$.

Progesterone, in different formulations, has also been used to prevent PTB and miscarriage since the 1960s [11]. Vaginal progesterone was initially prophylactically administered to women with historical risk factors for PTB. When compared to placebo, those treated with vaginal progesterone had a significantly lower frequency of delivery prior to 34 weeks [12]. Vaginal progesterone has also been shown to improve outcomes in the setting of TVUS-detected short cervix. In a large multicentre randomised control trial, the use of vaginal progesterone in women with a cervical length $<15 \mathrm{~mm}$ significantly reduced the incidence of PTB compared to placebo [13]. Cervical pessaries have also been shown to be an effective treatment for the prevention of PTB in women with cervical shortening [14].

Interest has increased recently in the combined use of these interventions to prevent PTB. A retrospective cohort study by Stricker et al. [15] did not show any benefit from the addition of vaginal progesterone to cervical pessary for prevention of PTB. A similar finding was also seen in a randomised controlled trial comparing vaginal progesterone and cervical pessary to vaginal progesterone alone [16].

Our study is a retrospective examination of the potential benefit of adding vaginal progesterone to cervical cerclage to prevent PTB in women with ongoing TVUS-confirmed cervical shortening despite the presence of a cervical suture. 


\section{Materials and Methods}

\section{Study design}

A retrospective case control study was performed of women with singleton pregnancies who underwent cervical surveillance by the Preterm Labour Clinic at the Royal Women's Hospital (RWH), Melbourne, in the years 2004-2014. Ethics approval was obtained from the RWH ethics committee.

Clinical records were used to identify women who underwent cervical cerclage alone versus those who were treated with both cervical cerclage and vaginal progesterone.

Retrospective data including demographic data, cervical length measurements, interventions and birth outcomes were collected from patient files and the clinical pathology viewer.

\section{Patient selection and methods}

Women referred to the Preterm Labour Clinic are identified as being at increased risk of preterm labour based on a history of PTB, cervical surgery, uterine malformation or TVUS findings of a shortened cervix ( $<25 \mathrm{~mm}$ ) on routine morphology scan.

The clinic protocol involves fortnightly visits from the 14th to 26th week of gestation for TVUS cervical length measurements and cervical swabs for microscopy and culture. During the research period, patients with a past history of documented cervical shortening and treatment with rescue cerclage were offered elective placement of cervical cerclage. Additionally, rescue cerclage or vaginal progesterone was offered to patients with a TVUS finding of a shortened cervix ( $<25 \mathrm{~mm}$ ) according to individualised indications for treatment and patient preference. Compliance with vaginal progesterone treatment advice was not formally monitored as part of the pre-term labour clinic protocol. Cervical cerclage was performed by a core small number of senior medical staff of the PTL clinic who were accredited for the procedure, with the decision for McDonald or Shirodkar cerclage being made according to clinician preference.

Following cerclage placement, patients continued to attend the pre-term labour clinic for serial TVUS cervical length measurements. Adjuvant vaginal progesterone therapy, at a dose of $200 \mathrm{mg}$ daily, was initiated if there was evidence of progressive cervical shortening of $<20 \mathrm{~mm}$ on subsequent TVUS cervical length measurements at the treating clinician's discretion. This became standard practice midway through the study period.

\section{Analysis and results}

The shortest TVUS measured cervical length of women in the two intervention groups was recorded. Cases in each intervention group were matched according to exact shortest cervical length measurements during the cervical surveillance period.

Each intervention group was compared with regard to birth outcomes 'gestational age at delivery' and 'birth weight'. Neonatal Apgar scores at 1 and 5 minutes along with mortality and intensive care admissions were also assessed. The differences in outcomes between the intervention groups were compared using paired t-tests. The data were transferred to an Excel spread sheet (Microsoft Corp., Redmond, WA, USA) and analysed using GraphPad Prism (GraphPad Software Inc., San Diego, CA, USA).

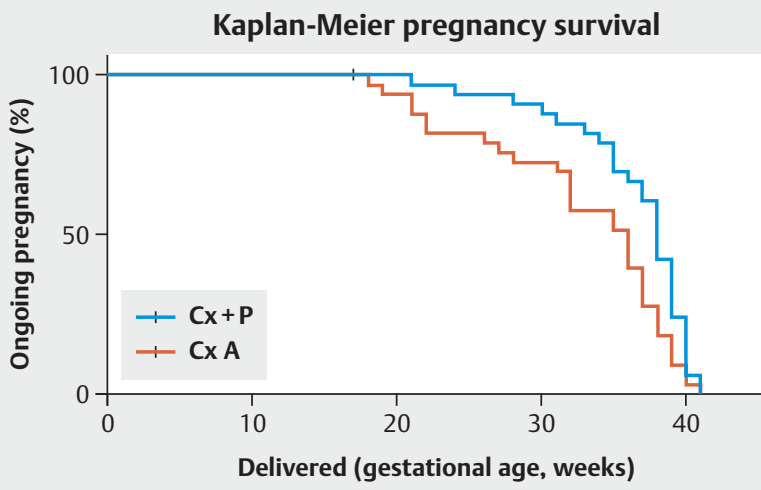

- Fig. 1 Kaplan-Meier pregnancy survival: statistical difference in ongoing pregnancies between intervention groups.

\section{Results}

A total of 66 women were identified; 33 women who underwent cervical cerclage alone were matched to 33 women who received both cervical cerclage and vaginal progesterone. Matching of cases was based on exact matching of the shortest recorded TVUS cervical length measurement during the period of cervical surveillance (14-26 weeks of gestation) with the average shortest cervical length measurements of both groups being $12.09 \mathrm{~mm}$. There was no difference in average maternal age, parity or smoking status between the intervention groups, with effective pairing seen on paired t-testing.

The majority of women across both intervention groups underwent cervical surveillance in the setting of previous PTB ( $\vee$ Table 1 ).

The average age of gestation for cervical cerclage placement was also similar in both intervention groups, at around 17 weeks' gestation. Vaginal progesterone administration commenced on average at 19 weeks, reflecting the nature of the use of this intervention as a further treatment for ongoing cervical shortening despite the presence of cervical cerclage.

\section{Delivery outcomes}

The progesterone and cerclage group had an average gestational age at delivery of $36.36(36+2)$ weeks with an average birth weight of $2830 \mathrm{~g}$. The cerclage alone group had an average gestational age at delivery of $32.64(32+4)$ weeks and an average birthweight of $2199 \mathrm{~g}$. This difference was statistically significant (paired t-test, $\mathrm{p}=0.0036$ ) This result was also reflected in the Kaplan-Meier curves, which show the statistical difference in the percentage of ongoing pregnancies between the intervention groups (• Fig. 1).

\section{Neonatal outcomes}

No significant differences were found between the intervention groups when comparing Apgar scores, perinatal mortality and intensive care admissions. 
- Table 1 Baseline characteristics and results.

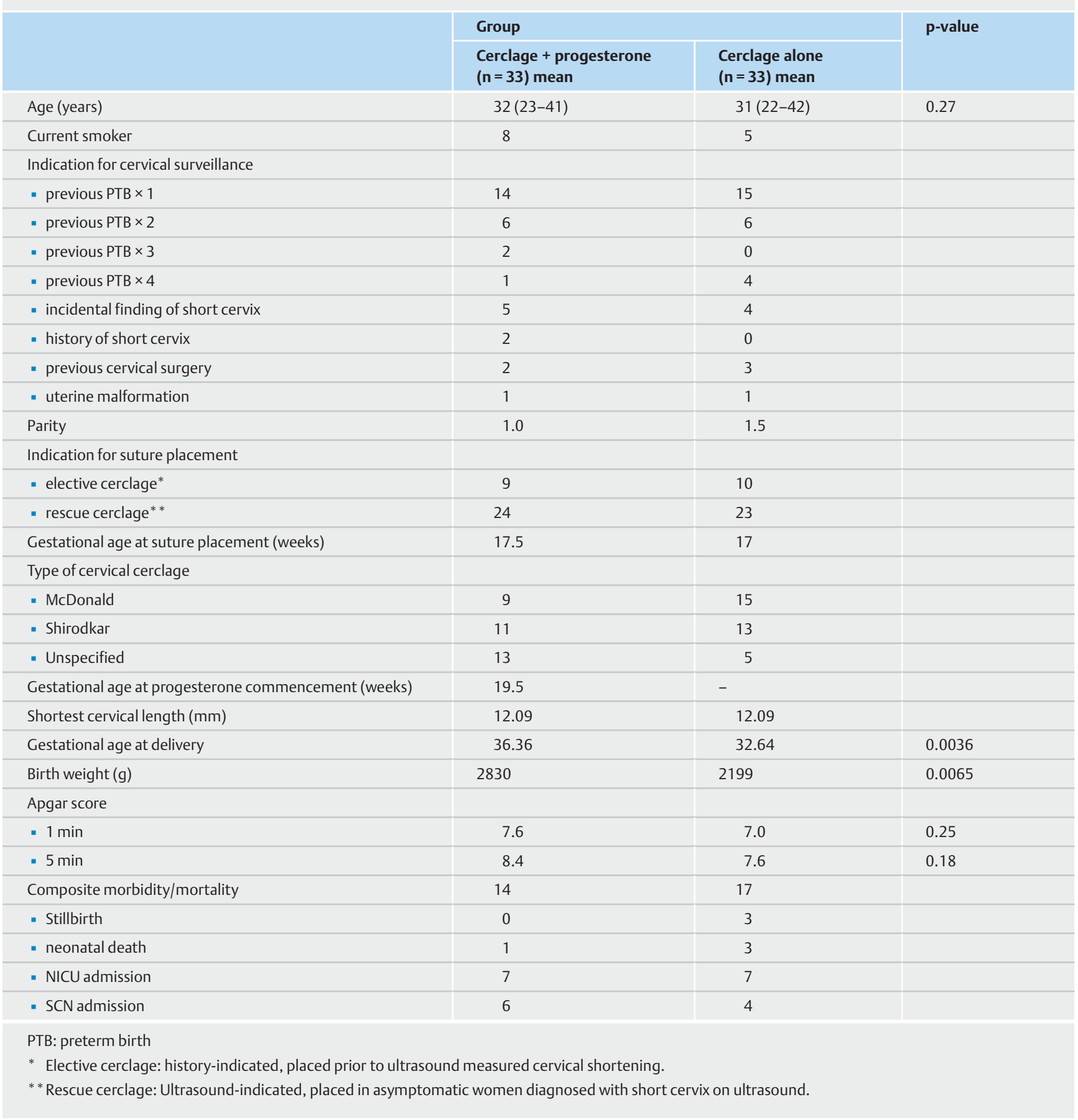

\section{Discussion}

The results of our study illustrate the potentially beneficial effects of adjuvant vaginal progesterone in a cohort of women at high risk of PTB. The high risk for PTB in this cohort is reflected by numerous risk factors. Firstly, the majority of patients included in the study had a history of PTB. Moreover, the average shortest cervical length of $12 \mathrm{~mm}$ and early cervical shortening, reflected by the average gestational age at suture placement of 17 weeks, further contributed to the risk for PTB. However, promisingly, the addition of vaginal progesterone in this high-risk cohort was seen to prolong pregnancy and reduce early pre-term delivery.

The use of progesterone concurrently with cervical cerclage for the prevention of pre-term birth has also been highlighted in a small number of studies.

The PREGNANT trial, which looked at the use of progesterone pessaries for the prevention of PTB in women with TVUS cervical lengths of $10-20 \mathrm{~mm}$, included 16 women who underwent emergency cervical cerclage post randomisation, with 10 women in the vaginal progesterone group and 6 in the placebo group. However, 
the small numbers of women who had adjuvant cervical cerclage in each intervention group were not statistically significant; patients were analysed in their randomised treatment groups on an intention-to-treat basis with no sub-analysis performed [17]. When Owen et al. [18] looking at cervical cerclage for the prevention of PTB, they included a sub-analysis of $39 \%$ of the study population that indicated an intention to use progesterone in conjunction with the randomised intervention. The progesterone referred to in the study was intra-muscular 17-alpha-hydroxy progesterone caproate, not vaginal progesterone. A sub-analysis was done of the women who intended to use progesterone; however compliance was not addressed. The analysis based on intention-to-treat found that there was no interaction between cerclage and the intra-muscular 17-alpha-hydroxy progesterone caproate.

As regards the concurrent use of vaginal progesterone and cervical cerclage, a study by Jung et al. showed promising results for the prevention of PTB. This retrospective cohort study looked at 53 women who underwent cervical cerclage after physical exam indicated the need for cerclage. Eighteen of these women also received concurrent vaginal progesterone from the time of cerclage placement. This was shown to be of benefit for prolonging pregnancy [19]. However, without objective cervical length measurements in this study, it is difficult to appreciate the risk for PTB in each intervention group and thus the true impact of the use of concurrent vaginal progesterone and cervical cerclage in this cohort. In addition, the rationale for the addition of vaginal progesterone in this study is unclear. Without a clear indication for the concurrent use of vaginal progesterone with cervical cerclage, it becomes difficult to appreciate any true benefit from its addition and thus to justify any potential risks and the cost of its use. It may be argued that vaginal progesterone is relatively safe and, given its established efficacy in prevention of PTB, perhaps combining it with another proven intervention such as cervical cerclage would result in greater efficacy of PTB prevention. Overall there is limited long-term data on the use of vaginal progesterone and any adverse maternal or foetal effects. There is some population data on the use of progestogens in infertility linked to increased rates of certain cancers in the offspring [20]. Although this has not been demonstrated with the use of vaginal progesterone, maternal side effects of discomfort and discharge and, importantly, the cost of administration must also be taken into account. Thus, a clear indication for the addition of vaginal progesterone needs to be established to justify its use as an additional intervention.

To the best of our knowledge this is the first study which has directly investigated the role of vaginal progesterone as a rescue adjunct in women with cervical cerclage and ongoing TVUS diagnosed cervical shortening.

In our study, vaginal progesterone was administered to women with TVUS evidence of progressive cervical shortening despite cervical cerclage, in particular women with cervical lengths $<20 \mathrm{~mm}$, a length at which the risk for PTB is thought to increase exponentially [5]. The increased risk of PTB with shortening cervical lengths has been shown in numerous studies. In the absence of cervical cerclage, lams et al. [4], using logistic regression analysis, showed that for each $1 \mathrm{~mm}$ increase in cervical length the odds ratio of PTB was 0.91 . Berghella et al. [21] similarly concluded that the risk of PTB decreased by $6 \%$ with every additional $\mathrm{mm}$ in cervical length.

This increased risk of PTB has also been seen in women with progressive cervical shortening despite cerclage. Drassinower et al. [22] showed that among women with cerclage, an accelerated rate of cervical shortening is associated with spontaneous PTB whereas patients with cerclage who delivered at term had a slower rate of cervical shortening. Sim et al. [23] demonstrated that there was a strong correlation between serial TVUS cervical length measurements post cerclage and gestational age at delivery. Thus, ongoing cervical surveillance of women with cervical cerclage has the potential to identify a cohort of women who have progressive cervical shortening and remain at increased risk of PTB.

International cervical screening guidelines suggest that there is insufficient data to encourage continued routine cervical length surveillance post cervical cerclage placement. This is thought to be primarily due to the lack of additional treatment options for a short cervix post cerclage [24]. Indeed, when looking at the placement of a repeat reinforcing cerclage, results have been mixed, even detrimental $[25,26]$. Our study provides some preliminary evidence that the use of adjuvant vaginal progesterone, used as a rescue intervention in women with cervical cerclage failure, may be of benefit in the prevention of early pre-term birth.

It is important to note that the generalisability of our results is limited by the small sample size and the retrospective case control study design. Interventions, although largely dictated by the preterm labour clinic protocol, were at times left to clinician discretion and patient preference, and despite our positive findings, a larger prospective investigation is required to confirm this potential benefit.

The intention of this study was a preliminary exploration of any potential benefits of adjuvant vaginal progesterone for failing cervical cerclage; thus, comprehensive data on neonatal morbidity or mortality was not addressed. Although the addition of vaginal progesterone to cervical cerclage did prolong pregnancy and improve birth weights, there was no difference in Apgar scores at the time of delivery. Given the small sample size, significant conclusions cannot be drawn from the neonatal morbidity and mortality data we presented, nor were neonatal outcomes followed up in the longer term. As a result, it is important that future research into this topic includes further evaluation of neonatal outcomes both in the long and short term, particularly as available 2year follow-up data on the use of prenatal vaginal progesterone for the prevention of PTB, albeit as a single intervention, suggests no long-term difference in neurological outcomes when compared to placebo [27].

Despite the limitations, our study provides supportive evidence for the beneficial effect of rescue adjuvant vaginal progesterone, in women with further cervical shortening despite cervical cerclage, for prolonging pregnancy. This finding is in keeping with the beneficial effects of vaginal progesterone seen when used concurrently with physical exam-indicated cervical cerclage. Our preliminary findings provide clinicians with some evidence for the therapeutic benefit of adding vaginal progesterone to failing cerclage, a clinical situation that currently presents a challenge for management. A randomised controlled trial would be useful 
to further investigate the role of vaginal progesterone in the prevention of PTB in women with very short cervical lengths despite cervical cerclage.

\section{Conclusion}

In summary, vaginal progesterone may improve outcomes in pregnancies with a short cervix despite cervical cerclage, including prolonged pregnancy and higher birthweight, compared to treatment with cerclage alone. This is the first study to specifically examine the use of vaginal progesterone as a rescue adjunct to cervical cerclage in women with TVUS evidence of ongoing cervical shortening despite cervical cerclage. Furthermore, it supports recent published data on the potential benefit of progesterone when used vaginally in combination with cervical cerclage. Further research in this area is required to characterise and confirm the potential benefits of the concurrent use of progesterone pessaries and cervical cerclage for the prevention of PTB and to address the effects on neonatal outcomes.

\section{Acknowledgements}

The authors would like to acknowledge Dr Shirlene Sim, Dr Kelly Hughes and Dr Kasia Michalak for their assistance with data collection and tabulation.

\section{Conflict of Interest}

The authors declare that they have no conflict of interest.

\section{References}

[1] Andersen HF, Nugent CE, Wanty SD et al. Prediction of risk for preterm delivery by ultrasonographic measurement of cervical length. Am J Obstet Gynecol 1990; 163: 859-867

[2] Andersen HF. Transvaginal and transabdominal ultrasonography of the uterine cervix during pregnancy. J Clin Ultrasound 1991; 19: 77-83

[3] Okitsu O, Mimura T, Nakayama T et al. Early prediction of preterm delivery by transvaginal ultrasonography. Ultrasound Obstet Gynecol 1992; 2: 402-409

[4] lams JD, Goldenberg RL, Meis PJ et al. The length of the cervix and the risk of spontaneous premature delivery. National Institute of Child Health and Human Development Maternal Fetal Medicine Unit Network. N Engl J Med 1996; 334: 567-572

[5] Heath V, Southall T, A Souka A et al. Cervical length at 23 weeks gestation: prediction of spontaneous preterm delivery. Ultrasound Obstet Gynecol 1998; 12: 301-303

[6] Green-Armytage VB, McClure Browne JC. Habitual abortion due to insufficiency of the internal cervical os: a preliminary report of seven cases treated by a modified Shirodkar technique. Br Med J 1957; 2: 128-131

[7] McDonald IA. Suture of the cervix for inevitable miscarriage. J Obstet Gynaecol Br Emp 1957; 64: 346-350

[8] Shirodkar JN. A new method for operative treatment for habitual abortions in the second trimester of pregnancy. Antiseptic 1955; 52: 299300

[9] Rush RW, Atlas RO, Jones KJ et al. A randomised controlled trial of cervical cerclage in women at high risk of preterm delivery. $\mathrm{Br}$ J Obstet Gynaecol 1984; 91: 724-730
[10] Lazar P, Gueguen S. Multicentred controlled trial of cervical cerclage in women at moderate risk of preterm delivery. $\mathrm{Br}$ J Obstet Gynaecol 1984; $91: 731-735$

[11] Keirse MJN. Progestogen administration in pregnancy may prevent preterm delivery. Br J Obstet Gynaecol 1990; 97: 149-154

[12] Fonseca EB, Bittar RE, Carvalho MH et al. Prophylactic administration of progesterone by vaginal suppository to reduce the incidence of spontaneous preterm birth in women at increased risk: a randomized placebocontrolled double-blind study. Am J Obstet Gynecol 2003; 188: 419-424

[13] Fonseca EB, Celik E, Parra M et al. Progesterone and the risk of preterm birth among women with a short cervix. N Engl J Med 2007; 357: 462469

[14] Goya M, Pratcorona L, Merced C et al. Cervical pessary in pregnant women with a short cervix (PECEP): An open-label randomised controlled trial. Lancet 2012; 379: 1800-1806

[15] Stricker N, Timmesfeld N, Kyvernitakis I et al. Vaginal progesterone combined with cervical pessary: A chance for pregnancies at risk for preterm birth? Am J Obstet Gynecol 2016; 214: 739.e1-739.e10

[16] Karbasian N, Sheikh M, Pirjani R et al. Combined treatment with cervical pessary and vaginal progesterone for the prevention of preterm birth: A randomized clinical trial. J Obstet Gynaecol Res 2016; 42: 1673-1679

[17] Hassan SS, Romero R, Vidyadhari D et al. PREGNANT Trial Vaginal progesterone reduces the rate of preterm birth in women with a sonographic short cervix: a multicenter, randomized, double-blind, placebocontrolled trial. Ultrasound Obstet Gynecol 2011; 38: 18-31

[18] Owen J, Hankins G, lams JD et al. Multicenter randomized trial of cerclage for preterm birth prevention in high-risk women with shortened midtrimester cervical length. Am J Obstet Gynecol 2009; 201: 375.e1375.e8

[19] Jung EY, Oh KJ, Hong JS et al. Addition of adjuvant progesterone to physical-exam-indicated cervical cerclage to prevent preterm birth. J Obstet Gynaecol Res 2016; 42: 1666-1672

[20] Hargreave M, Jensen A, Nielsen TS et al. Maternal use of fertility drugs and risk of cancer in children - A nationwide population-based cohort study in Denmark. Int J Cancer 2015; 136: 1931-1939

[21] Berghella V, Roman A, Daskalakis C et al. Gestational age at cervical length measurement and incidence of preterm birth. Obstet Gynecol 2007; 110: 311-317

[22] Drassinower D, Vink J, Pessel $C$ et al. The effect of cerclage on the rate of cervical shortening. Ultrasound Obstet Gynecol 2015; 46: 718-723

[23] Sim S, Da Silva Costa F, Araujo Júnior E et al. Factors associated with spontaneous preterm birth risk assessed by transvaginal ultrasound following cervical cerclage. Aus N Z J Obstet Gynaecol 2015; 55: 344-349

[24] McIntosh J, Feltovich $\mathrm{H}$, Berghella $\mathrm{V}$ et al.; Society for Maternal-Fetal Medicine (SMFM). Electronic address: pubs@smfm.org. The role of routine cervical length screening in selected high- and low-risk women for preterm birth prevention. Am J Obstet Gynecol 2016; 215: B2-B7

[25] Fox R, Holmesi R, James $M$ et al. Serial transvaginal ultrasonography following McDonald cerclage and repeat suture insertion. Aus N Z J Obstet Gynaecol 1998; 38: 27-30

[26] Baxter JK, Airoldi J, Berghella V. Short cervical length after history-indicated cerclage: Is a reinforcing cerclage beneficial? Am J Obstet Gynecol 2005; 193: 1204-1207

[27] Norman JE, Marlow N, Messow C et al.; OPPTIMUM study group. Vaginal progesterone prophylaxis for preterm birth (the OPPTIMUM study): a multicentre, randomised, double-blind trial. Lancet 2016; 387: 21062116 